\title{
Pierre Monbeig, um francês diante da geografia do movimento: um estudo sobre a obra Pioneiros e fazendeiros do Estado de São Paulo
}

\author{
Julia Cossermelli de Andrade ${ }^{1 \mathrm{e} 2}$
}

\section{Resumo}

Pierre Monbeig fez parte da missão francesa que fundou o curso de Geografia da Universidade de São Paulo. Seu nome está sempre intimamente relacionado com o método da Monografia Urbana e com a chamada Geografia Tradicional. Contudo, este artigo pretende discutir que durante as pesquisas realizadas pelo estudioso em nosso país, ele se depara com uma realidade em constante movimento que desafia seu método científico de compreensão de mundo. Há no geógrafo francês um sentimento de perplexidade diante da realidade de um país subdesenvolvido que gera um movimento de ajuste metodológico. Seu esforço é ainda provisório, experimental. Para demonstrar esse momento de desconforto e ruptura na história do pensamento geográfico, mergulhamos na tese de doutorado de Monbeig intitulada Pioneiros e fazendeiros do Estado de São Paulo, fruto de seus estudos empíricos, durante os anos em que esteve lecionando no Brasil.

\section{Palavras-chave}

História do pensamento geográfico, Pierre Monbeig, missão francesa na USP e frentes pioneiras.

1 Pesquisadora de pós-doutorado do Centro de Estudos da Metrópole Cem/Cebrap. Bolsista Fapesp. E-mail: juliadeandrade@gmail.com

2 Agradeço a Maurício Cardoso pelas críticas sempre inspiradoras. 


\title{
History of geographical thought, Monbeig Pierre, the French mission at USP and fronts
}

\author{
Julia Cossermelli de Andrade
}

\begin{abstract}
Pierre Monbeig participated in the French mission that funds the Geography courses at the University of Sao Paulo. His name has always been strongly associated to the Urban Monographic method, and with the so-called Traditional Geography. However, this article intends to discuss that in his research in our country (in Brazil), Monbeig is confronted with a reality that is in constant change, which challenges his scientific method of understanding the World. There is a perplex sentiment towards the reality of a developing nation that generates a methodic adjustment. This effort is still provisory, experimental. In order to demonstrate this moment of discomfort and rupture in history of the geographic line of thinking, we dive in a thesis of doctorate work of Monbeig, entitled Pioneers and farmers of the state of Sao Paulo, which is the result of his empirical studies during the years he spent lecturing in Brazil.
\end{abstract}

\section{Keywords}

History of geographical thought, Monbeig Pierre, the french mission at USP and fronts. 


$$
\mathcal{U}
$$


de viés marxista desenvolvida no Brasil nos anos subsequentes. Contudo, tal análise não se encaixa nos padrões da geografia tradicional, predominantemente descritiva, incapaz de travar uma interação dos elementos explicativos e um tanto avessa às questões sociais que se fazia até então. Pierre Monbeig, sensível ao mundo que o contornava, percebia o movimento e por esse motivo inquietava-se com a falta de instrumental teórico e analítico para capturar o real. O intuito desta reflexão é, então, apontar as "rupturas" presentes na obra de Monbeig, aplicando seu próprio termo "franjas" para iluminar a história do pensamento geográfico que, diante da complexidade do real, busca incansavelmente uma geografia do movimento. Para nós trata-se de um momento de passagem. Um bonito instante em que o pensamento de um geógrafo depara-se com limites metodológicos e que a busca da explicação do real exige superação e avanço científico.

Para isso, dividimos este artigo em três partes. Uma primeira denominada $A$ tese, em que apresentamos brevemente o texto e o contexto da obra: Pioneiros e fazendeiros do Estado de São Paulo. Elegemos alguns apontamentos - certamente preliminares - mas instigantes para se pensar a geografia brasileira. Na segunda parte, que chamamos de Estranhamentos, mostramos algumas passagens que denotam justamente o "desconforto" de um geógrafo francês frente à realidade de um país subdesenvolvido. Esse sentimento de perplexidade e impasse gera um movimento que não chega a ser absolutamente resolvido, mas é um ajuste provisório, uma experimentação. Assim, no terceiro momento Uma geografia do movimento - discutiremos mais detalhadamente as passagens do texto de Monbeig nas quais se pode notar a procura por uma geografia comprometida com interações sociais e sistemas explicativos. Nossa intenção é observar, nesse "andamento do texto", o movimento de estranheza e ajuste imperfeito na tentativa de explicar os fenômenos capturados pelo geógrafo francês. Desafios metodológicos oriundos da mais pura empiria foram capazes de gerar tamanha perplexidade em Pierre Monbeig que podemos notar suas marcas no seu texto.

\section{A tese}

Durante os anos em que Pierre Monbeig esteve lecionando no Brasil (1935 - 1946), na então Faculdade de Filosofia, Ciências e Letras da Universidade de São Paulo, ele esteve paralelamente envolvido em sua pesquisa sobre o pujante processo de ocupação do interior do Estado de São Paulo. Durante os anos da década de 1940, empenhou-se em conhecer os agentes responsáveis por abrir novas "frentes pioneiras". Essa pesquisa, 
redigida já na Europa, foi sua tese de doutorado, defendida na Sorbonne, em 1949, e premiada, no ano seguinte, como melhor tese pela Fundação Nacional das Ciências Políticas. Sob o título Pioneiros e fazendeiros de São Paulo a obra foi publicada no Brasil com a tradução do geógrafo Ary França (aluno de Monbeig) e de Raul de Andrade e Silva.

Trata-se de uma tese detalhada, confeccionada com um intenso trabalho de campo. Aliás, devemos ressaltar que o trabalho no campo é o baluarte central da moderna geografia trazida para o Brasil por Monbeig entre outros ${ }^{3}$. Para Maurício de Abreu, a partir de 1934 e durante um bom tempo, o trabalho de campo teria sido o trabalho geográfico par excelllence no Brasil.

Com efeito, diretamente influenciada pela Geografia Francesa, já tradicionalmente refratária à teorização, a Geografia Brasileira fez do trabalho no campo, do contato direto com a observação, uma atividade não apenas fundamental de pesquisa, como também de aprendizado. Não seria exagero afirmar que foi no trabalho "no campo" e não nas faculdades - que a primeira geração de geógrafos obteve, verdadeiramente, a sua formação. ${ }^{4}$

Maurício de Abreu define como Geografia Moderna a Geografia Acadêmica que, capitaneada particularmente por Pierre Monbeig, pretendeu por um fim definitivo na Geografia Enciclopédica que ainda "teimava em se manter por aqui" . Essa Geografia Moderna é conhecida

3 A Geografia Moderna se consolida no Brasil com a chegada dos mestres franceses. Por mais que ela já estivesse presente nos trabalhos de Delgado de Carvalho, nossa disciplina avança agora não apenas no ensino, mas principalmente na área da pesquisa. Aroldo de Azevedo afirma: "Criada a Universidade de São Paulo e, com ela a faculdade de Filosofia, passou a geografia a ser ensinada em nível superior, com o objetivo de formar bons professores para o magistério secundário e pesquisadores para o trabalho no campo" AZEVEDO, Aroldo. A geografia em São Paulo e sua evolução. Boletim Paulista de Geografia, São Paulo, n.16, p. 45-65,1954, p. 49 apud ABREU, Maurício. O estudo geográfico da cidade no Brasil: evolução e avaliação. Contribuição à história do pensamento geográfico brasileiro. Revista brasileira de geografia, Rio de Janeiro, v. 56, n. 1/4 p. 25, jan. /dez. 1994 .

Idem, ibidem. peito inclusive discutindo o papel da Sociedade de Geografia do Rio de Janeiro, do IBGE e dos congressos brasileiros de geografia na consolidação de uma geografia moderna no Brasil, em oposição a uma geografia descritiva e enciclopédica, feita majoritariamente nas escolas do país. 
nos dias atuais como Geografia Tradicional e se baseava em um método de trabalho em específico: a monografia ${ }^{6}$.

Durante os onze anos em que esteve no país, Monbeig buscou interpretar as transformações que assistia no Estado de São Paulo. Para ele a existência de zonas novas a serviço das atividades econômicas oferecia particular impulso ao desenvolvimento de São Paulo, "centro vital da economia brasileira". Apresenta em sua tese de doutorado, logo de início, a relação entre as transformações nas zonas rurais e as mudanças na capital, em franco crescimento:

O cultivo de terras há pouco recobertas de matas, a avançada constante dos pioneiros, a abertura de novas fazendas são fatores que agem com raro vigor sobre o conjunto da vida paulista. [...] Por outro lado, o crescimento dos bairros da capital reflete os impulsos do povoamento em tal ou qual direção; dependem as indústrias das matérias primas fornecidas pelas regiões pioneiras, assim como a absorção dos seus produtos nos espaços recém-povoados; seus operários provêm das terras cuja decadência, em grande parte, não é senão conseqüência da proximidade de vastas áreas intactas. ${ }^{7}$

Não somente esta relação causal, mas a própria organização dos capítulos da obra demonstra o quanto Monbeig estava vinculado à chamada geografia tradicional da Escola Francesa. O livro I está dividido em duas partes: a primeira, dedicada às condições naturais (relevo, clima, solos), finalizada por um breve sub-capítulo sobre as consequências da intervenção humana. A segunda parte é dedicada às condições históricas (meio histórico, fatores econômicos), mas, termina com uma reflexão um tanto estranha sobre as práticas geográficas de então: a psicologia do bandeirante ${ }^{8}$. Aldo Dantas aponta que essa breve abordagem já se constitui como um avanço significativo e um passo indiscutivelmente moderno no pensamento geográfico ${ }^{9}$.

6 A monografia monbeigiana continha comumente uma análise do sítio e posição da evolução histórica e das funções predominantes.

7 MONBEIG, Pierre. Pioneiros efazendeiros de São Paulo. 2 ed. Tradução de Ary França e Raul de Andrade e Silva. São Paulo: Hucitec, 1998. p. 21.

8 Assim como discute a psicologia do bandeirante, mais adiante Monbeig continua sua empreitada com a psicologia dos demais tipos humanos. Interessante ler o capítulo III, em que Monbeig conjuga causas econômicas com a psicologia do sitiante (precisamente p. 266 e 267 ) ou ainda quando ele analisa o fracasso do sistema de arrendamento por meio dos hábitos psicológicos dos fazendeiros, incapazes de lidar com o pequeno produtor em condições de liberdade (precisamente p. 285).

9 Inclusive, Dantas escreve que essa passagem não foi comentada durante $o$ ato de defesa da tese em Paris, o que demonstra uma inquietação e um desconcerto dos mestres fran- 
Contudo, a obra não se fecha aqui. Há ainda os livros II e III. No segundo, Monbeig analisa detalhadamente os Homens, entre eles os índios, os mineiros, os pioneiros, os colonos, os migrantes em todas as suas contradições. No terceiro, o autor mergulha na complexidade do mundo pioneiro que ele analisava naquele momento. São exatamente nessas duas últimas partes da tese que encontramos passagens interessantes que nos instigam a pensar na contribuição de Monbeig por meio de outra chave de compreensão. Falemos disso um pouco mais precisamente para ponderar a afirmação corriqueira de que "na regra monbeigiana os temas sociais assim como as relações de classe não são coisas que o geógrafo sabe e nem precisa estudar"10. Comecemos pela "psicologia do bandeirante" já citada acima. Monbeig reconhece a violência exercida por esses homens e apresenta seu estranhamento em relação à história do país e, logo em seguida, procura entender o porquê da glorificação em torno deste mito:

Num país cujo passado é curto, fica-se apaixonadamente preso ao que ele pode ter de prestigioso. Sendo um dos mais assombrosos da jovem história brasileira, o episódio das bandeiras impressiona muito as crianças.[...] Não que se ignore, nem mesmo que se esconda o que houve de brutal no comportamento dos bandeirantes, nem a sede de lucro que os animava. Mas, que episódio da história gloriosa, em não importa que país, deixará de estar manchado por algum crime? [...] Fato extremamente importante (a forte atração), pois se criou um mito do bandeirante, cuja a eficácia psicológica é incontestável. Quando se quer celebrar um fazendeiro, desbravador de matas, plantador de cidades, nenhum título melhor a deferir-lhe que o de bandeirante. ${ }^{11}$

O interessante nesta passagem é notar, como nos ensinou Dantas, que para Pierre Monbeig o modo de pensar e os modos de vida caminham juntos e devem ser pensados como um par. A geografia monbeigiana inicia

ceses face à abordagem apresentada. "Não há nenhuma dúvida de que esse estudioso foi formado na tradição das grandes teses regionais da Escola Francesa de Geografia, no entanto devemos reconhecer que sua obra vai além da simples descrição empírica: chega a um nível explicativo geral e constantemente enriquece a disciplina, introduzindo elementos outros para a discussão geográfica, como foi o caso, em sua tese, da pequena discussão que fez sobre a psicologia bandeirante, que passou quase desapercebida (ou foi propositadamente deixada de lado) pela banca examinadora, o que, segundo depoimentos, provocou uma certa indignação por parte do examinado". DANTAS, Aldo. Monbeig, paisagem e a geografia estigmática. Mercator-Revista de Geografia da UFC, Fortaleza, n. 2, p 71. 2002.

10 ABREU, Maurício. op. cit., p.zo.

11 MONBEIG, Pierre. op. cit., p. 121. 
uma abordagem interativa que mais tarde se consolidou abertamente nas ciências sociais: a relação entre representação e práticas sociais. "Monbeig escapa, assim, da crítica feita à tradição das monografias regionais acusadas de negligência na interação dos elementos explicativos"12.

No tocante aos índios, Pierre Monbeig também aponta sem piedade o conflito violento na relação entre eles e os pioneiros ${ }^{13}$. Os conflitos sociais estão escancarados assim como os conflitos para o acesso à terra analisados no texto. A questão dos grileiros é discutida, inclusive, à luz do sistema político e da legislação em vigor como a lei de Terras de 1850 e as que se seguiram nos anos subsequentes. As brechas que este sistema político e econômico abriram - para que o especulador de terras enriquecesse mais do que o plantador - são criticadas na tese. Isso nos faz discordar de algumas análises sobre a obra de Monbeig no tocante a sua incapacidade de tratar a questão social ou pelo menos ponderá-la.

Analisando o artigo de Monbeig de 1941, “O estudo geográfico das cidades", publicado na revista do Arquivo Municipal de São Paulo ${ }^{14}$, Maurício de Abreu afirma que, para Monbeig, as "relações entre os próprios homens" e o "processo social" não eram assuntos de interesse da Geografia. Abreu afirma isso apresentando duas citações. Primeiramente que, para a geografia monbeigiana, só era legítimo estudar os fenômenos sociais mensuráveis e cartografáveis. As diferenças entre as classes sociais, por exemplo, "são fatos sociais que o geógrafo não sabe e não precisa estudar"15. O segundo argumento apresentado por Maurício de Abreu, citando Monbeig, diz respeito à questão do dinheiro: "falar dos homens de suas casas é bom, mas se se esquece o dinheiro, nada se disse e apenas se mostram corpos inertes". Contudo, para Abreu, essa afirmação não constitui uma agenda de transformação, pois Monbeig pondera e descarta tal possibilidade de análise. Ele pretendia realçar a importância do capital financeiro no crescimento das cidades, mas julgando estar saindo do trabalho geográfico, logo cortou a discussão, dizendo que se distanciava demasiadamente do meio natural.

12 DANTAS, Aldo. op. cit., p. 7 l.

13 "Foram quase sempre sangrentos os contatos entre índios e pioneiros [...] Ficam os índios à espreita dos desbravadores, aproveitando-se da desatenção destes para atacálos [...] Eram assinaladas essas razias por atrozes morticídios, a flechadas e facadas. Por seu turno, respondiam os pioneiros aos ataques dos índios com igual brutalidade. Especializavam-se alguns dentre eles na organização de expedições punitivas, as dadas. Esses caçadores de índios, os bugreiros, eram conhecidos em todo o sertão. Pois se deslocavam de bom grado de um desbravamento para outro, a fim de empreender uma dada”. MONBEIG, Pierre. op. cit., p. 130-13ı.

14 ABREU, Maurício. op. cit., p. zo.

15 MONBEIG, Pierre. op. cit., p. 17. 
Aproveitando-se dessa mesma passagem de 1941 é que, contrariando o respeitável geógrafo carioca, enxergamos sim um início de ruptura. Pierre Monbeig não apenas não cortou a discussão, como aprofundou essas questões em sua tese do final da década de $1940^{16}$. No livro III, por exemplo, Monbeig analisa as necessidades e possibilidades do sitiante. Após uma clara distinção entre fazendeiro e sitiante pioneiro, ele inicia uma longa explanação sobre a questão da economia do trabalho e do sistema financeiro vigentes no Brasil. Oferece uma crítica precisa do momento da crise mundial pós 1929, que estancou os empréstimos dos bancos estrangeiros (gerando escassez de crédito que afetou os agricultores), e, em seguida, faz uma análise do sistema econômico e político, atacando principalmente a atuação do Banco do Brasil:

Assim, desde a instalação, o sitiante pioneiro é obrigado a contrair empréstimos. Desencadeia-se, desta forma, o mecanismo de uma armadilha de que os desafortunados não sairão jamais e que, de qualquer forma, amarrará por um tempo o pioneiro, por mais corajoso e empreendedor que ele seja. Terá que viver de empréstimos onerosos, pois os créditos agrícolas não é mais favorável ao sitiante do que o crédito fundiário. O Banco do Brasil trabalha de preferência com os fazendeiros que apresentam garantias mais seguras; mas quando atende aos sitiantes, os métodos utilizados são passíveis de crítica. Seu maior inconveniente é custar caro, pois o pequeno proprietário deve apresentar uma série de documentos oficiais, como título de propriedade, previsão de colheita e outros que os aspirantes a tabelião não desembacarão sem uma lentidão que será inversamente proporcional às gorjetas concedidas. ${ }^{17}$

Segundo ele, o pequeno proprietário, incapaz de ter acesso aos créditos dos bancos nacionais, prefere as instituições locais. Monbeig aponta motivos "psicológicos" desta escolha (os camponeses preferem os agentes conhecidos e próximos), ao mesmo tempo em que descortina um impasse normativo (necessidades de documentações e contrapartidas)

16 Não queremos iniciar aqui um debate valorativo dos diferentes momentos da geografia: a geografia tradicional é ruim e a geografia crítica, posterior a ela, é boa. Sabemos, inclusive, que esse não era o intuito de Maurício de Abreu. Ele é, aliás, bem explicito em seu texto quanto às injustiças que a geografia tradicional sofreu nos anos seguintes. $\mathrm{O}$ que desejamos tão somente é rediscutir os limites que a geografia monbeigiana ofereceu à nossa disciplina. Isso talvez nos leve a uma visão da história do pensamento geográfico certamente menos didático, contudo mais complexo e permeado de diferenças e contradições.

17 MONBEIG, Pierre. op. cit., p. 124. 
que leva a uma situação absolutamente perversa, em que o sitiante torna-se refém dos agentes de crédito:

A contrapartida desta generosidade (oferta de crédito sem exigência de documentos e garantias) aparente não deixará de ser dolorosa. Os juros dos empréstimos assim feitos são de ordem de 12\% ou $1 \%$ ao mês. As notas de compras dos fornecedores são, automaticamente, majoradas. As sementes, os adubos, os instrumentos de trabalho, os inseticidas e os alimentos custarão mais caro; mas o pobre pioneiro não se dará conta. O que sele sabe muito claramente é que o negociante, o "maquinista” ou seus intermediários, fazendo tão humanamente os empréstimos, adquiriram o direito, por vezes tácito, mas quase sempre por escrito, de lhe comprar toda a colheita. Pode-se garantir que eles não farão a oferta mais elevada nas cotações do dia, porque, recorrendo ao empréstimo, o sitiante perdeu o direito de dispor de sua safra. ${ }^{18}$

Assim como fez Sérgio Buarque de Holanda quatro anos antes, em Monções, de 1945, Pierre Monbeig discute o papel social do meeiro. Debruça-se sobre a questão da pobreza e a miséria dos migrantes, discutida na tese conjuntamente com a postura intolerante das elites paulistas ${ }^{19}$.

18 Idem, ibidem, p. 225.

19 Apesar de não encontrarmos nenhuma citação de Sérgio Buarque de Holanda na obra de Monbeig e nem do francès na obra do historiador brasileiro, ambos empreendem na mesma época uma análise da relação entre o fazendeiro brasileiro e o imigrante por meio de diferentes formas de trabalho como o do "meeiro" ou do trabalho livre. Relação descrita como conflituosa por ambos e com fortíssimas permanências da lógica escravista. Esse é, sem dúvida, um tema riquíssimo a ser explorado. Como dois pensadores contemporâneos, que habitavam a mesma cidade e estavam sensibilizados pelas mesmas questões, formulavam suas explicações? Qual o diálogo entre eles e/ou qual a explicação da ausência deste diálogo? Questões que nos despertam grande curiosidade. De qualquer maneira, deixamos aqui registrada a passagem de Monbeig muito próxima da de Holanda no que diz respeito às tradições escravistas e à questão do trabalho livre: "Houve greves, tiros e assassinatos, fatos episódicos, sem dúvida alguma, mas que contudo, revelam como não se ajustam facilmente os imigrantes e os fazendeiros, habituados a dirigir um pessoal sem exigências nem ambições. No fundo, para os plantadores, as somas pagas aos colonos, nunca foi mais do que uma espécie de soldo de subsistência. [...] Não se poderia esperar, do dia para a noite, a transformação das maneiras de pensar e de agir de uma sociedade que, em suma, não havia experimentado abalos profundos, desde o seu estabelecimento, ao sair de Portugal medievo. Foi em função das necessidades dessa sociedade, e sob a direção de governos nela diretamente derivados, que se organizou em São Paulo a imigração européia. Não surpreende, pois, que os imigrantes não tenham sido considerados como elemento do povoamento e sim apenas como braços para as lavouras". MONBEIG, Pierre. op. cit., p. 156-157. 
A descrição desta "imigração da miséria" revela um desconforto do autor face ao que via:

Triste migração essa das famílias que seguiram, freqüentemente a pé, do sertão até Juazeiro, a beira do Rio São Francisco. Subiam o rio em vapores mal arranjados, numa interminável viagem até Pirapora, ponto terminal da rede ferroviária. Outros vinham do sul da Bahia ou de Minas Gerais, atingiam igualmente a pé, a estrada de ferro em Montes Claros. Desta estação ou de Pirapora, inconfortável é a viagem de trem até São Paulo. Longe de ser desejável era o equipamento higiênico dos acampamentos onde se encontrava essa multidão miserável, seja nos portos do São Francisco, seja nas estações terminais. Assim quando desembarcavam na hospedaria dos imigrantes de São Paulo, estavam os "baianos" extenuados de fadiga, que se acrescentava à sua deficiente alimentação e incrível miséria. ${ }^{20}$

Logo em seguida, Monbeig apresenta as críticas dos paulistas a esse fenômeno que, num primeiro momento (quando as migrações eram de indivíduos isolados e celibatários) estavam centradas no fato de que o migrante pobre, ao recolher "modesto pecúlio", voltava para o sertão ao lado de sua mulher e de sua família. Para as elites paulistanas tratava-se de "êxodo de capitais". E pior, defendiam os paulistas, que esse vai e vem em nada contribuía para o povoamento. Mas as críticas ficaram ainda mais severas no segundo momento (quando a migração passou a ser majoritariamente de famílias), com os argumentos higienistas bem conhecidos entre nós até os dias atuais. Monbeig capta bem esse conflito e ainda aponta outra tensão social: o fato de que os trabalhadores baianos, ao aceitarem os baixos salários, provocavam uma imensa concorrência com os trabalhadores paulistas. Apesar de ponderar "que nem tudo era inexato nessas críticas", Monbeig chega à explicação que essa mão de obra proveniente dos estados do Norte e assalariada nas zonas novas prestava grandes serviços à colonização, já que era exatamente esse o trabalhador pobre (pouco exigente em salário e em condições de trabalho) que se dispunha a desbravar a floresta. Principalmente no momento em que a mão de obra estrangeira começou a deixar o campo em busca de ocupações urbanas.

Enfim, o que pretendemos aqui é fazer um exercício de leitura, no qual se possa ponderar afirmações tão conhecidas de que na Geografia Tradicional Brasileira e em especial a contribuição monbeigiana estava ausente os temas sociais e as relações de classe. Acreditamos que não,

20 Idem, ibidem, p. 151. 
elas estavam presentes, assim como, o desconforto que as desigualdades sociais despertam nos pensadores dedicados ao entendimento dos países subdesenvolvidos.

\section{Estranhamentos}

Pierre Monbeig chega ao Brasil trazendo em sua "bagagem" todo um arcabouço teórico e metodológico construído na tradição da academia francesa. Seu olhar europeu se choca quando se depara com uma realidade distinta daquela encontrada no velho mundo dos anos 1930. Apontar primeiramente esse estranhamento é revelador para que possamos, em seguida, chegar ao que chamamos de "momento de ruptura", no qual o pensamento de Monbeig se supera e avança. Nossa hipótese aqui defendida é a de que esse geógrafo francês não seguiu a risca as doutrinas da geografia tradicional. Se assim fosse, ele não apontaria certas problemáticas discutidas na tese. Quem sabe nem mesmo as notaria! Contudo, ele não apenas toca em tais questões como busca uma solução explicativa, mesmo que provisória, para elas. Há, assim, um momento de impasse, de perplexidade, seguido de outro, que não é uma formulação acabada e sim um ajuste imperfeito, uma experimentação, uma adequação. Esse estranhamento é revelado primeiramente como um incômodo. Ele "reclama" das condições de trabalho, da falta de dados, da confusão estatística, da falta de profissionalismo dos funcionários municipais, apontando todos esses fatores como obstáculos para a própria análise:

Está longe de ser fácil o trabalho de geógrafo, nas zonas pioneiras do Brasil. Sem desprezar as dificuldades materiais, a grande distância entre a cidade de São Paulo e as regiões novas, as deficiências de circulação, a impossibilidade de viajar durante a estação das chuvas que corresponde a das férias universitárias, há outras que não enfrentam no mesmo grau os geógrafos acostumados a trabalhos nos países velhos. ${ }^{21}$

As reclamações são diversas: primeiramente a falta de documentação cartográfica, em geral, incompleta e escassa. Quando existia, o material era tão cheio de erros que se tornava "quase inútil". Aponta ainda que os dados fornecidos estavam velhos e incompletos e que as fontes estatísticas eram de origem duvidosa. "Nos municípios, o pessoal encarregado

21 Idem, ibidem, p. 18. 
de recolher o material de base, em regra é destituído das qualidades desejáveis para esse delicado trabalho"22. Ele nota, inclusive, um esforço sistemático em "harmonizar cifras" entre municípios vizinhos o que, sem dúvida, deslegitima toda e qualquer análise quantitativa. Outra reclamação é a instabilidade das circunscrições administrativas:

"Até os últimos anos, podiam as autoridades do estado criar, suprimir, fundir à vontade os municípios e os distritos de paz, que servem de base territorial para a elaboração estatística. Eram freqüentemente modificados os nomes, tornando muito difícil, entre dois recenseamentos, proceder a comparações" ${ }^{23}$.

Mas admite que são atributos de regiões de povoamento em curso. Um segundo estranhamento do francês nos trópicos refere-se à questão da escala. As dimensões abordadas no Brasil são distintas das que ele estava acostumado na Europa, onde se deparava com conjuntos menores. Esta mudança de escala não era apenas uma questão política - de tamanho de país - mas dizia respeito a uma formação natural e geomorfológica:

No Brasil, como na maior parte dos países da zona intertropical, as mesmas características geográficas são encontradas em grandes extensões. As mesmas rochas, os mesmos solos e as mesmas formas topográficas estende-se por centenas de quilômetros. Uma unidade climática regional pode ter as dimensões da França e só o avião, com a velocidade de que é capaz, pode desfazer a impressão de que não se viu uma só paisagem durante toda a viagem. Ao invés da variedade a que está habituado, o europeu descobre espaços intermináveis, cuja uniformidade é o traço dominante. ${ }^{24}$

Ainda na primeira parte da tese, em que Monbeig dedica-se à descrição das condições naturais, ele questiona o conceito aplicado ao relevo brasileiro de "serra". Para o geógrafo o termo é inadequado, optando por utilizar chapada ou espigão. Nesse caso, o estranhamento (a forma e a formação geológica não condiz com o conceito formulado para outra geomorfologia) é seguido, de imediato, por nova conceituação mais precisa e adequada:

22 Idem, ibidem, p. 18.

23 Idem, ibidem, p. 18.

24. Idem, ibidem, p. 33 . 
Abusou-se outrora da expressão serra para designar essa forma de relevo, a que o nome chapada conviria melhor. Mas um outro termo lhe convém mais ainda: espigão. Esta palavra, utilizada para designar a linha de cumeeira dos telhados, aplica-se, com muita propriedade, a uma elevação que é também linha de separação das águas. Quando suas escarpas foram vistas pela primeira vez pelos que penetravam pelos vales, a impressão foi de montanhas, de onde a expressão serra. Posteriormente, a utilização do solo concentrou-se nas elevações e a palavra espigão entrou na linguagem corrente. Diz-se "espigão da Paulista" para designar as elevações em que correm os trilhos da Co. paulista de Estradas de Ferro, "espigão da Sorocabana" etc. ${ }^{25}$

Com certeza, a escolha do recorte do estudo "franjas pioneiras" inevitavelmente levou o geógrafo a pensar motivos, causas, razões que explicassem esse movimento tão complexo, no qual os homens estavam motivados a seguir a diante na colonização. Uma primeira aproximação de Monbeig com o impasse levou-o a compreender "como" era esse pioneiro e por que, diferentemente do tipo europeu, ele se sujeitava a situação de intensa mobilidade. Monbeig conclui que a existência de um "mito bandeirante" seria capaz de gerar a motivação necessária às empreitadas. Essa seria uma característica particularmente latino-americana: "Diz-se tudo de um homem, quando se diz que ele é um verdadeiro bandeirante. Levemos em conta essa ênfase latina e não nos espante essa promoção indireta e póstuma do bandeirante a colonizador. No dinamismo do fazendeiro-pioneiro, a massa popular encontra a lembrança da legenda do bandeirantismo"26.

Isso explicava para o autor não somente o comprometimento das camadas mais pobres com a marcha (que não dispunham de outras opções financeiras capazes de garantir a sobrevivência própria e de suas famílias), mas também o envolvimento das elites "estudadas":

No curso de minhas viagens, muitas vezes encontrei moços, nascido nas grandes cidades, antigos alunos da escola de Medicina, de Agronomia, de Engenharia, em São Paulo ou no Rio de Janeiro, que viviam duramente; no meio de gente rude e bruta, e experimentavam evidente alegria na vida sertaneja. Nisso contava muito o lado esportivo. Mas também a sensação de criar, o sentimento de manter uma tradição e o orgulho de contribuir para engrandecer o seu país. Há nos brasileiros, mais frequentemente os de Minas

25 Idem, ibidem, p. 40.

26 Idem, ibidem, p. 121-122. 
Gerais e de São Paulo, uma espécie de instinto que os impede [sic] sempre a diante, para além da civilização. ${ }^{27}$

Assim, essa psicologia do conquistador (o gosto pelo risco e pelo jogo) poderia explicar muito do desejo empreendedor pioneiro. Ele cita também o papel desempenhado pela publicidade em torno do "eterno eldorado", justificando o impulso pouco ancorado em dificuldades reais:

Isso também talvez corresponde à inclinação para a jogatina eu campeava em toda a América Latina, senão mesmo em todo continente americano. Lançar-se na abertura de uma fazenda nova, equivalia a arriscar a sorte, liquidar um negócio proveitoso, porém obscuro, para empreender outro novo, contando com o valor da terra e com as probabilidades do mercado, correspondia a uma audaz especulação. Muitos o experimentavam; esqueciam-se os que malogravam, pensando-se só no sucesso de que toda a gente falava: o modelo invejado era o do "bandeirante de hoje", o grande homem de tal ou qual zona, celebrado pela pequena imprensa local que conquistou fortuna e prestígio político. ${ }^{28}$

Mais adiante o autor aprofunda a questão, dizendo que o motor deste movimento é explicado além do gosto pelo jogo, ao mesmo tempo, por uma resignação fácil ou um movimento um tanto passível ao que parece inevitável segundo ele: "Muitas vezes parte-se, porque parentes e vizinhos já partiram. Sem nem saber por que, segue-se o exemplo dado. Numerosos pequenos proprietários de lavouras de café, situados nas zonas novas, onde a produção continuava proveitosa, apesar disso vieram a comprar lotes de terra na zona pioneira" 29.

Finalmente, ele analisa a questão do mito do Eldorado, presente na psicologia dos povos americanos, onde "Fique rico" é a palavra de ordem coletiva. Ele, inclusive, denomina essa postura de "otimismo mundo novo" ${ }^{30}$. No trecho abaixo podemos notar como o autor explica essa característica típica dos países do continente americano:

O paulista de velha estirpe acompanhava orgulhosamente a marcha para o oeste. Comprazia-se em contar como seu avô abandonara a

27 Idem, ibidem, p. 122.

28 Idem, ibidem, p. 123.

29 Idem, ibidem, p. 123.

zo Idem, ibidem, p. 319 . 
fazenda do Vale do Paraíba pela região de Campinas; em seguida seu pai abrira uma plantação na zona de Ribeirão Preto; e ele, por sua vez, continuava a desbravar a floresta na Alta Paulista ou ao norte do Paraná. Realizava o filho do imigrante, em uma geração, o que a família fizera em três etapas. Para ele, tratava-se também de prosseguir uma tradição, a dos pais que vieram arriscar a sorte, e era dentro deste espírito que ele continuava. A bem dizer sofriam todos a magia dos grandes espaços livres e experimentavam todos a ardente convicção de que a fortuna lá o esperava. [...] Em todos os países novos, do norte ao sul do continente americano, observa-se a sedução pelas terras novas e a paixão pelo ganho rápido do dinheiro. ${ }^{31}$

Nesse trecho, fica clara a relação íntima entre o que Pierre Monbeig enxergava como modos de pensar e o modo de vida, ou seja, as "representações" e as práticas sociais.

Uma quarta passagem, na qual não se esconde o "olhar europeu", é quando Monbeig analisa o trabalho agrícola desenvolvido no Estado de São Paulo. Para ele é "chocante" verificar como ao lado de fazendas já formadas subsiste um "trabalho agrícola primitivo". Escreve ele: "Permanece o otimismo do caboclo a repetir que no Brasil plantando dá. Com efeito, tudo cresce em uma terra roxa recentemente desflorestada e, para um pioneiro vindo de um estado do sul do Brasil, a terra do norte do Paraná é uma terra preguiçosa. Para que comprar um arado, quando bastam alguns golpes de enxada" ${ }^{32}$ ?

Um quinto aspecto, que também gerou certo estranhamento, foi a questão das moléstias e de saúde. Um capítulo inteiro é dedicado à situação sanitária do mundo pioneiro. Nele Monbeig relaciona as enfermidades tanto com a questão social quanto ambiental a que estavam sujeitos os pioneiros. A grande constatação é a falta de saneamento básico, levando a casos alarmantes de enfermidades ou agravando moléstias que poderiam ser tratadas sem grandes perigos. Uma situação curiosa que o autor descreve nas décadas de 1930-1940: a falta de calçados para a população pobre. Isso faz lembrar, sem sombra de dúvidas, o personagem tão polêmico Jeca Tatu, de Monteiro Lobato: caipira sem sapatos, homem "molenga" que vivia com vermes na barriga $^{33}$. Sapato era artigo raro e quase nunca disponível para crianças:

31 Idem, ibidem, p. 123-124.

32 Idem, ibidem, p. 250.

33 "A nossa montanha é vítima de um parasita, um piolho da terra, peculiar ao solo brasileiro [...] Este funesto parasita da terra é o caboclo, espécie de homem baldio, seminômade, inadaptável à civilização [...] Começa na morada. Sua casa de sapé e lama faz sorrir aos bichos que moram em toca [...] Só ele não fala, não canta, não ri, não ama. Só 
As populações rurais brasileiras estão habituadas a andar descalças, devido a mediocridade dos salários. É uma raridade encontrar uma criança de sapatos. As mais altas taxas de infecção encontram-se no grupo de idades de dez a vinte anos, isto é, escolares e os jovens que ajudam os pais na roça. Artigo caro, o calçado é reservado aos adultos e os jovens ficam com a ancilostomose, o amarelão, a que estão resignados. Daí sua fraca resistência às moléstias contagiosas, benignas em indivíduos saudáveis. ${ }^{34}$

Nesse mesmo capítulo, outra informação causa assombro ao autor, assim como ao leitor da atualidade: $o$ alto preço pago para a assistência de um médico. Chamar um "doutor" para fazer um parto em um sítio, afirma Monbeig, pode custar os ganhos de um semestre do trabalhador braçal. Para o autor, as misérias vividas pelo povo não são de responsabilidade total do “meio", apesar de não negar sua influência ${ }^{35}$ :

O pioneiro está tão despreparado diante da doença como o caboclo que ficou para trás. Ambos tem a ignorância de higiene e estão freqüentemente diante da mesma impossibilidade pecuniária de se tratarem [...] Causa espanto e admiração a energia dos pioneiros paulistas, quando, como inúmeros outros homens do Brasil, eles convivem com a doença. É certo, porém, que os pesados tributos das moléstias é inevitável nessa zona já à margem dos climas quentes e úmidos. Atribui-se ao meio responsabilidade pelo miserável estado sanitário; mas a permanência de tal situação não lhe pode ser imputada. ${ }^{36}$

ele, no meio de tanta vida, não vive...”. Trecho do conto publicado no livro LOBATO, Monteiro. Urupês. 16. ed., Ed. Brasiliense, 1971. p. 140-141. Todavia, foi publicado anteriormente no jornal $O$ Estado de São Paulo, em 1914. Há um amplo debate sobre essa descrição violenta de Lobato. Esse pode ser considerado a gênese do trabalho de Monteiro Lobato. Ele, fazendeiro do interior paulista, incomodado com as queimadas feitas pelos caboclos, escreve para tal jornal que, vendo a qualidade literária, publica o texto fora da sessão de queixas. Lobato, anos mais tarde, pede desculpas aos caboclos quando descobre que a "indolência do Jeca" era resultado de enfermidades e todos os tipos de verminoses. O personagem passa, então, a ser uma espécie de "garoto propaganda" das políticas governamentais para "calçar" a população.

34 MONBEIG, Pierre. op. cit., p. 331.

35 Aqui poderíamos pensar as relações entre os determinismos e os possibilismos geográficos de ontem e de hoje na chamada "geografia médica". Recortes interessantes que instigam futuras investigações.

36 MONBEIG, Pierre. op. cit., p. 335 . 
Uma sexta estranheza que destacamos aqui é a indignação de Monbeig frente ao papel dos especuladores de terra e da grande passividade da população face ao processo gerador de desigualdades. Ele discute isso por meio do que chamou de "fatores psicológicos e o papel dos indivíduos" na formação urbana e na concorrência entre localidades. Quando avalia a lógica especulativa pautada unicamente no lucro de poucos, ele escreve:

Pouca gente, aliás surpreende-se com tais métodos, nem se aventura a formular julgamentos sobre essas especulações de grande envergaduras ou sobre esse controle da economia urbana por um só indivíduo. No fundo são mais admirados que censurados os poderosos da terra, que a gente modesta imita, em sua humilde esfera. A especulação atrai especulação. Assim, procura-se comprar, vender, resgatar e revender casas e lotes urbanos, aproveitando a excelente publicidade feita em torno do patrimônio, pelo seu dinâmico fundador. Sem dúvida, é normal a valorização de imóveis, numa aglomeração em pleno surto, mas não tarda a revestir-se de caráter artificial. ${ }^{37}$

Monbeig captou muito bem essa falta de crítica na sociedade brasileira quando a "coisa pública” é apropriada pelos ricos. Ele reitera tal aspecto quando trata da reserva florestal do Morro do Diabo. A grande dificuldade em assegurar e defender o interesse público, principalmente quando ele se opõe ao interesse privado dos grupos historicamente privilegiados. Situação que, tristemente, persiste até os dias atuais, cercados de novos consensos e outras facilidades.

Finalmente, discutiremos o último estranhamento. A questão da disposição ao crédito é, para nosso autor, um assunto particularmente importante para interpretar as sociedades americanas. Para Pierre Monbeig essa questão - e toda a complexidade financeira advinda dela - é fator central para o entendimento do movimento da "franja pioneira". Assim, é a opção pelo crédito que explicará a especulação fundiária, agindo em conjunto com as normas bancárias no Brasil. Por isso, Monbeig alerta seu leitor europeu sobre as particularidades dos países novos:

A concorrência atinge melhor ao pioneiro, quando procura atraí-lo pelas facilidades de pagamento. Não nos esqueçamos de que estamos no continente americano, onde tudo se compra a crédito. As empresas de loteamento menos sólidas e mais apressadas em atingir o lucro

37 Idem, ibidem, p. 356 . 
esperado, pedem um pagamento inicial de 50\% do preço da terra e não dão senão um ano ao sitiante para terminar as prestações. ${ }^{38}$

Monbeig descreve a causa que motiva os homens a seguirem a diante na marcha pioneira, associando intimamente duas causas: o "mito de Eldorado", associado a variadas causas na estrutura econômica, agravada pela sede do lucro rápido. A instabilidade da agricultura brasileira é tratada por meio de uma análise complexa, em que se levanta uma série de fatores. Ele busca uma lógica coerente além das fronteiras habituais das análises geográficas. Critica as políticas dos bancos estatais (Brasil e Banco do Estado), dos empréstimos privados, que formam um sistema no qual o pequeno produtor e a população pobre são sempre atingidos. Com isso, aponta os discutíveis baluartes sobre os quais está erguida a sociedade brasileira, entregue à instabilidade.

A terra tropical, frágil e maltratada por homens que têm pressa em enriquecer, é a primeira responsável pela instabilidade. Mas os resultados não seriam tão graves sem as próprias responsabilidades dos homens: a ignorância dos sitiantes, a incerteza muito frequente quanto aos títulos de propriedade, a pobreza, a desorganização do crédito, o controle do comércio por alguns grupos, tanto brasileiros como estrangeiros e a força da especulação. ${ }^{39}$

\section{Uma geografia do movimento}

Nesta última parte do artigo, discutiremos as passagens nas quais Monbeig lidou com as dificuldades teóricas e práticas de trabalhar com o movimento. A mobilidade e o dinamismo da realidade empírica que ele estudava o levou a uma série de "reacomodações" no método. Um primeiro sintoma é a crítica a conceitos postos. O segundo, é um exercício em fazer conexões explicativas maiores e mais complexas. Para finalmente encontrarmos uma série de categorias analíticas interrelacionadas e dinâmicas.

Monbeig estava absolutamente consciente quanto à impossibilidade de tratar a realidade que via com o arcabouço teórico de que dispunha. Por

38 Idem, ibidem, p. 227.

39 Idem, ibidem, p. 320. 
isso, adverte seu leitor, na abertura da obra, de que não poderia seguir as normas da monografia regional, mas optaria por novos caminhos:

Mudanças administrativas, incertezas estatísticas, vazios cartográficos, eis tantas conseqüências de um estado de coisas que, a cada dia, se modifica. Tão rápidas são as transformações que tudo que se pode escrever a respeito entra logo na história. Por isso, foi o próprio movimento que eu tentei descrever e explicar; não era possivel elaborar uma monografia regional, por isso procurei compor o estudo de uma sociedade em movimento, de preferência um estudo de gênero de vida. ${ }^{40}$

Ele percebia empiricamente que o dinamismo era nota central desta realidade. Em uma passagem poética ele descreve a paisagem (não apenas visual, mas sonora) em que revela esse inegável movimento:

Mesmo que se fechasse os olhos à paisagem, o viajante não escaparia à impressão da nova zona: seus companheiros se comprazem em citar cifras prestigiosas, que testemunham o surto das cidades atravessadas, a evocar o heróico nascimento delas, ou a narrar os bons negócios que nelas fizeram, os golpes de especulação bem sucedidos. Noutros vagões, outros viajantes, em andrajos, carregando pobres trouxas e arrastando crianças de olhos fundos, contemplam, atemorizados, essas paisagens estranhas; vêm da Bahia, de Pernambuco, ou do Ceará, atraídos pela fama lendária da região pioneira paulista. Ouvia-se falar português, mas com zetacismo do japonês ou o sotaque do alemão. Os corredores dos trens ficam abarrotados. Nas estações numerosa multidão se comprime sobre as plataformas e as jardineiras com os estribos já apinhados de passageiros esperam a chegada do trem de São Paulo, para conduzir novos recém-chegados até as terras de que esperam mil maravilhas. Tudo é alvoroço, tudo é confusão, tudo é dinamismo. ${ }^{41}$

Para Monbeig a "mancha pioneira" é constituída exatamente desta instabilidade, por isso afirma: "Por toda parte, na cidade como no campo, sente-se que nada se estabiliza, nada é definitivo, e que economia e povoamento se solidarizam com a mancha pioneira, que inexoravelmente arranca rumo a Oeste, centenas de quilômetros" $"$

40 Idem, ibidem, p. 19. Grifo nosso.

4,1 Idem, ibidem, p. 22-23. Grifo nosso.

4,2 Idem, ibidem, p. 21. 
Frente ao mundo em transformação é de se esperar um exercício de questionamento de conceitos estabelecidos. Destacamos brevemente três passagens nesse sentido. No capítulo III, Monbeig apresenta a diferenciação que Deffontaines ${ }^{43}$ estabelece entre "zonas pioneira" e "sertão". Esse último seriam as zonas ainda intocadas, grandes espaços contínuos, recobertos pela grande floresta, que Deffontaines havia localizado em meados de 1934 ao longo do rio Paraná. Contudo, Monbeig questiona: "Quinze anos depois, não é mais exato falar de sertão paulista, pois tudo que permanecia intacto até a grande depressão econômica foi invadido pelos derrubadores de mato e hoje faz parte da zona pioneira" (p. 205). Eis aqui um exemplo inspirador de como a geografia avança quando comprometida com o real. Talvez seja disso que Milton Santos falava, mais de quarenta anos depois, ao defender a necessidade do trabalho empírico. Pois se estamos atentos ao "decurso da história, ao desabrochar de novas realidades, com a renovação dos fatos", ou seja, recolhendo no real o que ele é, é que possibilitamos que os conceitos e as categorias possam se renovar mantendo viva a nossa disciplina ${ }^{44}$.

Uma segunda discordância é agora com um outro francês, Reclus, que escreveu no século XIX que, na América do Sul, as vias férreas precedem as habitações. Monbeig nega a perpetuação dessa ideia, pois constata que, naquele momento (década de 1940) as cidades surgem mesmo que distantes das conexões e das vias férreas.

Uma terceira passagem sobre este tema é bem mais sutil e, ao mesmo tempo, muito mais complexa. Diríamos que se trata de um passo significativo para um pensador que parte da análise da paisagem, do visível. Em determinado momento da tese, Monbeig percebe que as lavouras de café continuam se expandindo, mesmo após a crise de 1929. Contudo, ele defende que essa continuidade geográfica não esconde uma transformação no processo. Na paisagem se vê a expansão, a continuidade geográfica das lavouras, porém a estrutura produtiva, o processo se modificou.

43 A obra referenciada é DEFFONTAINES, Pierre. Pays et paysages de l'État de Saint-Paul (Brésil). Première esquisse de division régionale. Annales de géographie, 1936, tome XLV, p. 50-71 e 160-174.

44. A passagem completa é: "Necessidade do trabalho empírico: a primeira e mais importante é a de estar atento ao decurso da história, ao desabrochar de novas realidades, com a renovação dos fatos. O trabalho empírico é indispensável. Trata-se, de fato, de um trabalho teórico-empírico. É preciso ir recolher no real o que ele é, peça por peça, mecanismo por mecanismo, ilação por ilação, e desse conjunto de coisas e das relações que as animam, examinando a luz de conjuntos maiores, extrair significações que, sendo particulares ao caso estudado, tragam igualmente, ainda que escondidas em seu bojo, uma dimensão universal, e encerrem um germe ou uma promessa de abstração factualmente construída”. SANTOS, Milton. Alguns problemas atuais da contribuição marxista à geografia. In: . (Org.). Novos rumos da geografia brasileira. São Paulo: Hucitec, 1993. p. $13^{2}$. 
A onda do café continuou, portanto, a propagar-se, seguindo as normas anteriores, isto é, progressão nos planaltos dos arenitos de Bauru e procura terra roxa. Mas a continuidade geográfica não esconde a transformação radical do processo. Se antes da crise de 1929 procurava-se ainda aumentar as superfícies, para aumentar a produção, hoje essa não é mais uma preocupação que sensibilize os plantadores. A questão é muito mais angustiante, porque se trata, para eles, de salvar o café paulista e, se possível, reconstituir um estoque de plantas comparáveis às do passado. A diminuição dos rendimentos, a destruição dos cafezais e também a concorrência de outros produtores foram tais, que se tornou urgente reconstituir o capital que são os cafeeiros. Assim, o avanço para oeste não é mais uma progressão, mas uma espécie de fuga. ${ }^{45}$

Nesse sentido, nos permitimos evocar novamente os ensinamentos de Milton Santos quando propõe a não separação entre forma, função, estrutura e processo. Quando se trabalha assim, como foi o caso de Monbeig, é possível captar a mudança. "O fenômeno é nominalmente o mesmo, mas sua natureza mudou. Trata-se então de outra coisa" ${ }^{46}$.

O movimento obrigou o autor francês a propor conexões explicativas bem maiores. Esta ampliação se deu em três sentidos. Em primeiro lugar, ele não mais restringe as explicações aos fenômenos ocorridos na região. As causas internacionais são centrais e determinantes ao lado das causas nacionais, paulistas, regionais. A explicação do fenômeno da expansão cafeeira se dá por meio de uma razão local (brasileira) e outra global (interesses do outro lado do atlântico, por intermédio da expansão capitalista ou ainda do "planeta dos brancos"). Note as duas citações abaixo:

Essas causas [movimento de conquistas dos planaltos ocidentais] não são apenas paulistas, nem somente brasileiras. A marcha ininterrupta da frente de povoamento, não passa de um aspecto da exploração do planeta pelos brancos. Tanto em suas origens, como em sua continuidade, ela se prende, por sobre o oceano, às condições técnicas, econômicas e políticas do mundo. Complexo jogo de circunstâncias locais, de ordem natural e social, e de oportunidades muito mais gerais, que é preciso deslindar, se se quiser compreender por que os

45 MONBEIG, Pierre. op. cit., p. 261. Grifo nosso.

46 SANTOS, Milton. op. cit., p. 135. 
paulistas invadiram os planaltos ocidentais, ao findar o século XIX, e por que, desde então, não se deteve essa arrancada. ${ }^{47}$

Não era inútil assinalar esses aspectos históricos da expansão paulista. Diante de tantos fatores favoráveis, compreende-se melhor que os fazendeiros não tenham tido senão o objetivo de plantar. Reduzindo-se a marcha para o oeste a um fenômeno local, contentar-se com explicá-la por circunstâncias estritamente brasileiras, seria restringir abusivamente seus quadros e não enxergar mais que seus aspectos estreitos. Desde o seu início, a marcha para oeste foi um episódio da expansão da civilização capitalista, surgida nas duas margens do Atlântico. Ambas não cessam de ser solidárias. ${ }^{48}$

Um segundo sentido de ampliação das conexões notou-se quando Monbeig propôs uma explicação intersetorial. Ou seja, como os fazendeiros do café tornam-se também empreendedores, tanto na abertura de companhias de estradas de ferro quanto de empresas de imigração. Ele analisa, por exemplo, o papel de grandes fazendeiros como Martinho Prado Jr., que juntamente com seus 12.000 alqueires e 3.400.000 cafeeiros, passou também a organizar uma sociedade de imigração, indo pessoalmente várias vezes à Itália para recrutar colonos. Era também Deputado na Assembléia provincial onde, claro, defendia os interesses dos fazendeiros. Esse senhor ainda estava envolvido ativamente com o comércio exportador e, ao lado do irmão Antônio, fundou a Companhia Paulista de Estradas de Ferro. Já Antônio Prado, foi ministro da Agricultura, prefeito de São Paulo, banqueiro, fazendeiro, comissário de café e dirigiu a Companhia Paulista durante trinta anos. Para entender a lógica do sistema, Monbeig propôs uma análise do que na atualidade chamamos nos estudos sociológicos de redes sociais:

Casamentos, camaradagens entre colegas de escola, relações de negócios apertavam os laços entre elas [famílias poderosas] [...] Tinham todos os mesmos interesses profundos e estavam de acordo quanto às grandes linhas que a administração deveria seguir. Até a década de 1930, foram grandes fazendeiros, de algum modo, os dirigentes de São Paulo. Confundia-se o interesse coletivo com seu interesse de classe. Esse fato sociológico liga-se a geografia do movimento pioneiro. ${ }^{49}$

47 MONBEIG, Pierre. op. cit., p. 94 .

48 Idem, ibidem, p. 105.

49 Idem, ibidem, p. 141. 
E uma terceira faceta das conexões explicativas mais ampliadas e complexas é quando ele abandona a explicação de causa-efeito e enxerga uma relação mais solidária nos fenômenos da "franja pioneira". A especulação fundiária alimenta e é alimentada pelo cultivo do solo:

As empresas do loteamento não põem em prática uma política de preços com escala tão ampla. Mas aproveitam-se das valorizações, porque os sitiantes que especulam com seu lote, revendendo-o com lucro, ou vai comprar um lote urbano que dá mais lucro à Companhia, ou recomeça nova especulação, comprando lotes mais distantes, maiores ou mais numerosos. O enriquecimento dos especuladores não deixa de ser, pelo menos indiretamente, solidário com o cultivo dos solos. Os loteadores compreenderam rapidamente que partido poderiam tirar desse fato e isso os instiga cada vez mais a organizarem cuidadosamente o planejamento rural. ${ }^{50}$

Ao nosso ver o auge da explicação da geografia do movimento se dá quando o autor afirma que a crise mundial de produção é o estancamento do processo, mas também sua alavanca. Pois as crises marcam uma desaceleração do avanço pioneiro, todavia, ao mesmo tempo, traz o "germe da nova fase".

A crise econômica que atravessou o mundo, o Brasil e, particularmente o Estado de São Paulo, foi um elemento importante para a análise de Monbeig. Ele avalia da seguinte forma a relevância das crises: "Quando se busca um remédio para o mal, pode-se recolher, nos períodos de depressão, uma documentação importante. Este tipo de informação, que não é inquietante quando tudo marcha a contento, é para nosso estudo um marco obrigatório" ${ }^{51}$.

Assumido este caminho explicativo que encara as contradições e os paradoxos oriundos dos períodos de crise, o autor inicia um caminho interpretativo muito rico. Uma passagem estimulante do texto está no trecho em que o autor relaciona o movimento do interior do estado e as fragilidades dos países subdesenvolvidos numa complexa articulação com uma economia mundial, também marcada por crises. É no movimento desses três elementos e nos seus abalos que ele discute as crises não apenas como inibidoras, mas também (e acima de tudo) como estimuladoras de mais movimento. Aqui a comparação entre as zonas pioneiras e a realidade da França, por exemplo, um "velho país rural”, são interessantes:

5o Idem, ibidem, p. 237. Grifo nosso.

$5^{1}$ Idem, ibidem, p. 166. 
no caso brasileiro, as zonas novas são bem mais vulneráveis às crises mundiais, “não existe amortecedores”. Já na realidade europeia a própria economia regional ou mesmo nacional impede que os camponeses fiquem tão expostos "à fome voraz" dos interesses internacionais.

Nascido no momento em que se instalava a economia capitalista, o movimento de conquista dos planaltos ocidentais não cessou, pois, de progredir, a despeito das crises inerentes aos sistemas e até mesmo por causas destas crises. As depressões econômicas, que balizam esses três quartos de século, procederam das zonas pioneiras. Mas, cada uma delas suscitou oportunidades novas que, cada vez mais, reajustaram o mecanismo. Assim se confunde o dinamismo da frente de povoamento paulista com o da economia mundial. Num velho país rural, os abalos da economia raramente acarretam o abandono brutal das culturas do solo; está o camponês por demais ancorado, para que a borrasca o arraste; participa ele de uma economia regional ou nacional, que amortece o choque dos acontecimentos internacionais. Nas zonas novas, não existe amortecedores, pois a produção se imita a alguns produtos destinados à exploração e diretamente submetidos às vicissitudes do mercado mundial. A franja pioneira é o ponto de encontro dos apetites e ambições tanto nacionais como estrangeiros. O que a expõe a ser duramente atingida pelas crises, mas ao mesmo tempo lhe permite recuperar muito depressa sua vitalidade..$^{52}$

Partindo da especificidade das "franjas pioneiras" Monbeig propõe, para dar conta da realidade, o esboço de um novo método de estudo, no qual o geógrafo deve observar com detalhe o tripé da produção, da mão de obra e dos transportes de maneira conjunta. Estamos convencidos que aqui reside uma das rupturas mais ricas do pensamento monbeigiano, que agora avança da lógica da monografia regional para um processo mais estrutural:

Se é verdade que, a qualquer momento, não importa que zona pioneira deve ser estudada sob triplo aspecto da produção, da mão de obra e dos transportes, em tempo de crise esses problemas são singularmente mais graves. A crise também marca, como já vimos, uma desaceleração do avanço pioneiro e, ao mesmo tempo, traz germes da nova fase. ${ }^{53}$

$5^{2}$ Idem, ibidem, p. 118-119. Grifo nosso.

53 Idem, ibidem, p. 166. 


\section{Palavras finais}

Pierre Monbeig foi um geógrafo comprometido com seu mundo. Procurou compreender o Brasil e a dinâmica que o inquietava sem poupar esforços. E, por sorte da geografia, ousamos afirmar que o Brasil fez bem para nosso "bom francês", pois apresentou a ele um desafio que a Europa ainda não enfrentava de maneira tão violenta. Isso o fez superar obstáculos no seu pensamento e no seu método. Por isso, o conceito de franja que ele tanto utiliza - "uma fronteira que progride irregularmente em direções confusas" - pode ser empregado também para explicar o lugar do seu livro Pioneiros e fazendeiros do Estado de São Paulo no pensamento geográfico. Sua tese representa um avanço em relação à tradicional geografia francesa, ensinada por ele próprio em suas Monografias regionais e urbanas. Ele mesmo estava ciente disso. Essa obra propõe novos olhares e métodos e outras categorias para os estudos geográficos. Após Monbeig outros também fizeram suas contribuições, partindo das monografias em direção a uma geografia mais complexa: Valverde, Aroldo de Azevedo, entre outros pensadores, trouxeram à história do pensamento geográfico particularidades e especificidades.

Nosso artigo está definitivamente despido de pretensões conclusivas. Nele buscou-se apenas fazer uma leitura cuidadosa (e carinhosa) de uma obra importante para a geografia brasileira e mostrar que existiu movimentos heterogêneos dentro da geografia tradicional, em geral, ignorados pelas classificações mais didáticas. Além disso, esta reflexão nos serviu de estímulo para pensar na capacidade de explicação do mundo que a geografia possuiu em determinados momentos. Qual a capacidade dos geógrafos em dialogar com seus contemporâneos de dentro e de fora do campo geográfico? Dentre as questões que nasceram deste texto, uma em particular vale ser enunciada: Por que Sérgio Buarque de Holanda não aparece como interlocutor na tese de Monbeig? Como já anunciamos, Monções tratava exatamente do Estado de São Paulo e havia sido publicado quatro anos antes da defesa do doutorado de Monbeig. Qual era a interlocução de Monbeig com os pensadores brasileiros como Sérgio Buarque e Caio Prado Jr.? E com seus companheiros de missão, como o comunista Jean Maugüe e o socialista Lévi Strauss que, inclusive, partiram com ele de Marselha em 1935, rumo às terras brasileiras?

Compreender os desdobramentos do pensamento geográfico, seus diálogos, suas crises e seus avanços é tarefa sempre estimulante para todos nós, herdeiros desta tradição complexa e singular. 